\title{
Aprendizagens musicais informais em uma comunidade de prática: um estudo no grupo de maracatu Arrasta Ilha
}

\author{
André F. Marcelino \\ Viviane Beineke \\ (UDESC)
}

\begin{abstract}
Resumo: Este trabalho teve como objetivo investigar as dinâmicas de aprendizagem musical que se estabelecem no grupo de maracatu Arrasta Ilha, de Florianópolis-SC, Brasil. A fundamentação teórica da pesquisa combina o conceito de comunidade de prática (Wenger, 2008) e de práticas de aprendizagem musical informal (Green, 2002). Foi realizado um estudo de caso de abordagem qualitativa. Os resultados da pesquisa apontam cinco dinâmicas de aprendizagem musical: escuta e tirar de ouvido, encontros casuais e organizados, observação e imitação, onomatopeias solfejadas, e aprender osmoticamente. Tais dinâmicas são potencializadas num ambiente de aprendizagem que se configura como uma comunidade de prática, onde os participantes compartilham uma paixão em comum: o interesse pela prática musical do maracatu.
\end{abstract}

Palavras-chave: educação musical, comunidade de prática, aprendizagem musical informal, grupo de percussão, maracatu

INFORMAL MUSICAL LEARNING IN A COMMUNITY OF PRACTICE: A STUDY OF THE MARACATU GROUP ARRASTA ILHA

\begin{abstract}
The purpose of this study is to investigate the dynamics of musical learning that are found in the maracatu group Arrasta I/ha, in Florianópolis-SC, Brazil. The theoretical foundation for the research combines the concept of community of practice (Wenger, 2008) and informal musical learning (Green, 2002). A case study was conducted with a qualitative approach. The results of the study indicate five dynamics of musical learning: listening and playing by ear, casual and organized encounters, observation and imitation, solfege onomatopoeias, and learning osmotically. These dynamics are given potential in a learning environment that is established as a community of practice, where the participants share a common passion: the interest for the musical practice of maracatu.
\end{abstract}

Keywords: musical education, community of practice, informal musical learning, percussion group, maracatu 


\section{Introdução}

Perspectivas socioculturais da educação musical vêm problematizando e ampliando discussões sobre processos de aprendizagem e práticas musicais, em pesquisas que caracterizam-se por construir objetos de estudo contextualizados social e culturalmente. Nessa abordagem a educação musical vem ampliando seus espaços de investigação para múltiplos contextos, valorizando e legitimando as experiências musicais em diferentes ambientes (Andrade, 2011; Arroyo, 1999. 2002a, 2002b; Del Ben, 2003; Green, 2000, 2002, 2008; Müller, 2000; Oliveira; Harder, 2008; Russel, 2002, 2006; Torres; Araújo, 2009; Wazlawick; Maheirie, 2009; Wille, 2005).

O reconhecimento de múltiplos espaços que transcendem a escola tem ajudado a identificar e assumir a complexidade e também o conjunto de saberes que constitui a área de educação musical como campo de conhecimento. Segundo Arroyo (2002a, p. 98), “em qualquer prática musical estão implícitos o ensino e aprendizagem de música, que nenhuma prática é melhor que outra, mas que cada uma deve ser compreendida no seu contexto de construção e ação". Além disso, Oliveira e Harder, (2008, p. 79) argumentam que "as práticas metodológicas presentes nas escolas apresentam características e valores que são encontrados naquelas desenvolvidas pelos mestres das manifestações culturais".

Nessa perspectiva, esta pesquisa se propôs investigar as dinâmicas de aprendizagem musical entre os participantes de um grupo de maracatu, chamado Arrasta I/ha, de Florianópolis/SC, Brasil. O Arrasta I/ha é um grupo de dança e percussão que pratica o maracatu de baque virado, manifestação popular que teve origem em Pernambuco. Atualmente o grupo é formado por pessoas entre 18 e 57 anos de idade; varia também no tempo de ingresso, havendo pessoas que ingressaram há poucos meses e aquelas que o frequentam há 10 anos, independentemente de experiência e habilidade musical. O grupo ensaia aos domingos na Universidade Federal de Santa Catarina (UFSC) e tem por objetivo principal difundir a cultura do maracatu de baque virado. É frequente a entrada de novos integrantes para participar das atividades do grupo, cuja rotatividade nos encontros é elevada, variando de dez a quarenta pessoas. 


\section{Comunidades de prática e processos de aprendizagem musical informal}

A fundamentação teórica foi construída com base nos conceitos de comunidade de prática de Etienne Wenger (2008) e dos processos de aprendizagem musical informal apresentados e analisados por Lucy Green (2002).

Uma comunidade de prática é definida por Wenger como "grupos de pessoas as quais compartilham um interesse ou uma paixão por algo que fazem e aprendem como fazê-lo ainda melhor à medida que interagem regularmente" (Wenger, 2006, site, p. 1). O autor utiliza três dimensões para associar a prática a uma comunidade: engajamento mútuo, empreendimento conjunto e recursos compartilhados (2008, p. 73). Este conceito caracteriza-se pelo engajamento mútuo dos participantes envolvidos em ações cujos significados são negociados entre si como um processo coletivo de interação entre esses membros, resultando num sentimento de comunidade que o autor denomina empreendimento conjunto. Por mais que haja desentendimentos e desarmonia em alguns momentos, esse sentimento de comunidade os mantém unidos. Os recursos compartilhados entre os participantes é o terceiro elemento e se refere às rotinas, palavras, ferramentas, histórias e às formas como os membros dessa comunidade fazem e resolvem as coisas. Nessa perspectiva, entende-se que aprender música em uma comunidade de prática potencializa aprendizagens significativas, construídas colaborativamente de maneira a permitir diferentes níveis de participação, acomodando diferentes estilos de aprendizagem e níveis de desenvolvimento (Sawyer, 2008, p. 57).

Lucy Green (2002) investiga a natureza das práticas de aprendizagem informal, atitudes, valores, habilidades e conhecimentos de alguns músicos populares. A autora apresenta a preocupação e o interesse voltados ao que esses processos e práticas oferecem à educação musical formal. Seu trabalho contribui para esta pesquisa pelos aspectos observados nos processos de aprendizagem musical informal desses músicos. A 'enculturação musical' é um aspecto fundamental de toda aprendizagem musical, formal e informal, como um processo de aquisição de conhecimento, como uma imersão do indivíduo na 
música e nas práticas musicais, tocando, cantando, compondo e ouvindo (Green, 2002, p. 22).

Segundo Green (2000; 2002) a técnica de aprendizagem musical mais importante usada pelos músicos populares é a escuta e imitação de gravações, o que chamamos de "tirar músicas de ouvido". Os músicos populares observam e imitam uns aos outros; falam sobre a música e formam bandas desde os primeiros estágios da aprendizagem. Nessas interações, eles imitam e trocam ideias, conhecimentos e técnicas. Os músicos populares consideram importantes questões não-musicais, como as qualidades pessoais, enfatizando a empatia nas relações, a cooperação, a confiabilidade, o compromisso, a tolerância e uma paixão compartilhada pela música. A autora argumenta que o conhecimento de tais métodos de aprendizagem informal pode contribuir significativamente com a educação musical formal, provocando reflexões sobre os sentidos da aprendizagem musical em diferentes contextos e as formas como apreendemos e ensinamos música.

Estes referenciais, bem como as problematizações decorrentes, orientaram também a construção metodológica da pesquisa, que buscou articular diferentes técnicas de coleta de dados que permitissem compreender as dinâmicas de aprendizagem musical do grupo Arrasta I/ha.

\section{Caminhos metodológicos}

Este trabalho é de abordagem qualitativa, sendo realizado um estudo de caso. As técnicas de coleta de dados utilizadas nessa pesquisa foram a observação participante, o registro em áudio e vídeo, diário de campo, documentos e grupo focal. Alves-Mazzotti (2001, p. 167) orienta para que as primeiras etapas do trabalho de campo, a observação participante seja, “não apenas o principal, mas o único instrumento de investigação". Dessa forma, nas primeiras observações participantes não foram realizados registros em vídeo e áudio, sendo produzidas notas de campo após as observações. Desta maneira foi possível a inserção no 
grupo como participante e perceber quais situações seriam interessantes registrar para contemplar o foco da pesquisa.

O grupo focal (GF) foi fundamental para perceber e coletar informações, impressões e perspectivas sobre o processo de aprendizagem musical do grupo, além de integrar os demais dados coletados (Gatti, 2005). Participaram do grupo focal participantes mais experientes, intermediários e iniciantes. O convite foi realizado para todos os participantes, no entanto contou com a presença de 9 membros do grupo, são eles: André, Charles, Igor, Janaina, Julia, Leojorge, Ronan, Sonia e Xanda.

A observação participante, registros de áudio e vídeo foram realizadas de janeiro a setembro de 2013, e o grupo focal foi realizado em maio do mesmo ano. O processo de análise de dados envolveu a transcrição do grupo focal e também de partes das gravações em vídeo realizadas nas observações. As categorias foram sendo gradativamente construídas a partir desse conjunto de dados gerados na pesquisa, incluindo também as notas de campo e documentos diversos disponíveis no site do grupo.

\section{O grupo de maracatu Arrasta I/ha}

O grupo de maracatu Arrasta I/ha focaliza a dimensão musical do maracatu de baque virado, não possuindo vínculo com os aspectos culturais e religiosos relativos à brincadeira do maracatu. Atua desde 2002 em Florianópolis, e é um grupo aberto à comunidade e ao público em geral. Desde sua formação, a UFSC é o local de ensaios e atividades do grupo, tanto pela acessibilidade, centralizado geograficamente na cidade, como por ser o grupo composto, principalmente naquela época e até pouco tempo, por estudantes universitários. Há muitos estudantes no grupo, mas não é uma hegemonia. A faixa etária do grupo é bem ampla, e vem aumentando desde o início de sua formação; atualmente há estudantes universitários, graduados, pós-graduados, pósgraduandos de diferentes cursos, funcionários públicos, autônomos, artistas, músicos e até aposentados. 
O repertório do grupo é composto por toadas de maracatu. Toada é o nome dado à música do maracatu de baque virado, basicamente a letra e a melodia. É cantada com o acompanhamento dos instrumentos de percussão e tem uma estrutura geralmente de perguntas e respostas, onde alguém canta solo e o coro responde ou repete o trecho (Guerra-Peixe, 1956, p. 49). Em seu repertório o Arrasta I/ha contempla toadas de quatro diferentes nações ${ }^{1}$ de maracatu de Recife, toadas compostas pelos próprios integrantes, ex-integrantes e também por alguns mestres de maracatu que compuseram especialmente para o grupo. Os instrumentos utilizados pelo grupo são os mesmo usados pela maioria dos grupos e nações de maracatu: alfaia, caixa, tarol, gonguê, abê, timbau e mineiro.

Nesse período de observação foram classificadas três dinâmicas gerais das atividades do grupo: os ensaios, as oficinas e as apresentações. Os ensaios são realizados aos domingos das 15 às 19 horas, geralmente estendendo para uma reunião até às 20h. O grupo ensaia dentro da UFSC, próximo ao Centro de Convivência, ao lado da Banca de Arte-Ocupação, onde o grupo guarda os instrumentos (Figura 1).

Figura 1: Espaço de ensaio do Arrasta Ilha e a Banca de Arte-Ocupação (Fonte: Marcelino, 2014, p. 102)

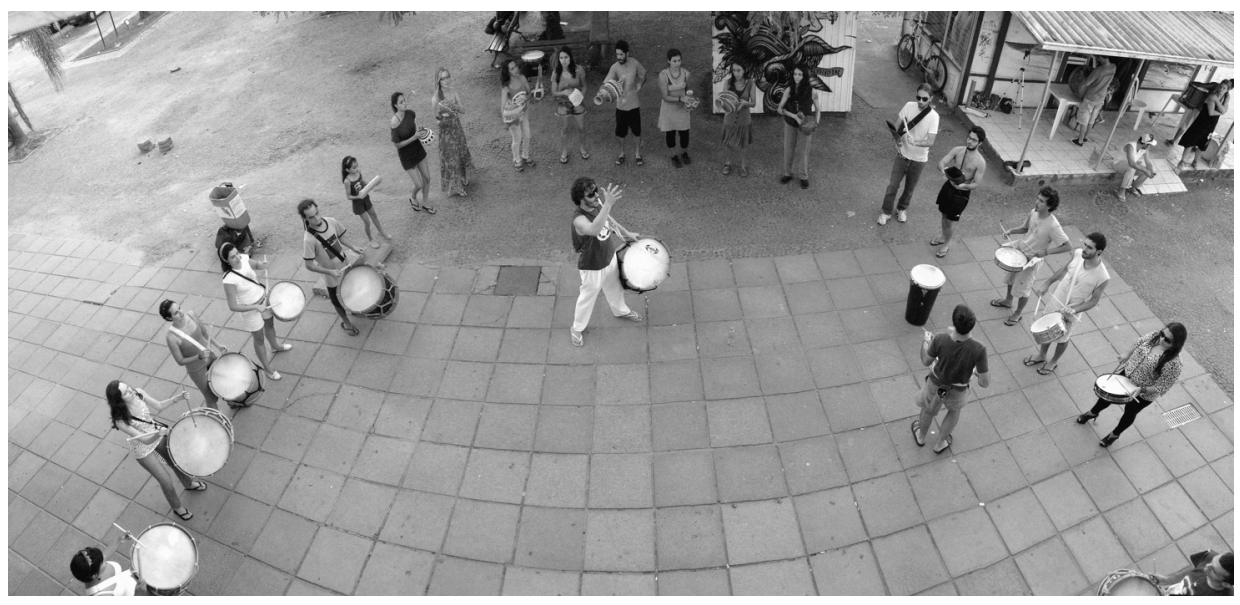

${ }^{1}$ Nação é um grupo de maracatu que tem vínculos religiosos associados às práticas e que toca o maracatu de baque virado. 
As oficinas promovidas pelo grupo acontecem de duas formas. A primeira forma ocorre no início dos ensaios de domingo, das $15 \mathrm{~h}$ às $17 \mathrm{~h}$ onde frequentemente entram alunos novos e a prática musical é voltada aos iniciantes, a chamam de Oficina de Iniciantes. E o grupo promove oficinas com mestres de maracatu, e também com outros grupos de cultura popular.

As apresentações são divididas, segundo o grupo, em apresentação “de palco" e "de rua". Nas de palco optam por uma formação mais compacta de 7 a 10 pessoas. Quase sempre revezam os instrumentos para que mais integrantes toquem. Na apresentação "de rua” vão todos os participantes, variando de 10 a 30 pessoas, depende da disponibilidade de todos. Nas apresentações e ensaios do período do carnaval é quando o grupo toma a maior proporção, chegando a 50 pessoas entre batuqueiros e dançarinos.

Foi observado que os ensaios são espaços de aperfeiçoamento, prática, ensino e aprendizagem musical, onde também se realizam oficinas direcionadas aos membros do grupo. As apresentações, "de rua" e "de palco”, oferecem espaço e oportunidade para os iniciantes se inserirem no grupo, além de atrair novos participantes que, ao assistirem, acabam se interessando em conhecer e participar. $\mathrm{E}$ as oficinas com os mestres promovem o aperfeiçoamento do grupo, proporcionando novos conhecimentos e refletindo nos ensaios, nas Oficinas de Iniciantes e nas apresentações. Assim, essas três atividades promovidas pelo grupo Arrasta Ilha se relacionam mutuamente, através da participação e do engajamento dos participantes.

\section{A comunidade de prática Arrasta I/ha}

Os participantes se reúnem todo domingo pra ensaiar, realizam apresentações, promovem oficinas para aperfeiçoamento e têm um mesmo objetivo, que é a prática musical e a difusão do maracatu. O Arrasta I/ha é um grupo de pessoas que compartilham o interesse e uma paixão em comum pela prática do maracatu, aprendendo, ensinando e difundindo-a na medida em que os participantes interagem entre si. 
No grupo há formas de lideranças, na ausência de algumas pessoas outros representantes assumem o papel de orientação do grupo. É independente da representatividade dos integrantes que o engajamento e a prática de cada um se transforma em uma resposta comunitária, num sentimento de que estão envolvidos com algo em comum. Isso é o que Wenger (2008) chama de empreendimento conjunto, um elemento negociado por todo o grupo sem ser determinado por uma pessoa ou regras.

É durante essas atividades musicais que os integrantes do Arrasta I/ha compartilham seus conhecimentos; ao conviver com essa rotina de ensaios, oficinas e apresentações do grupo, aprendem um conjunto de recursos, como: os gestos que simbolizam arranjos ou a forma como se deve tocar um instrumento, palavras e histórias do contexto do maracatu. E esse repertório compartilhado, descrito por Wenger (2008, p. 83) sofre modificações à medida que novos integrantes passam a interagir e pertencer a essa comunidade, pois esses novos recursos são constantemente negociados entre os participantes.

\section{Dinâmicas de aprendizagem musical do grupo Arrasta //ha}

Ao descrever e refletir sobre como se estabelecem as dinâmicas de aprendizagem musical nas atividades musicais do grupo e nas interações sociais dos participantes, foram categorizadas cinco dinâmicas de aprendizagem musical: escuta e tirar de ouvido, encontros casuais e organizados, observação e imitação, onomatopeias solfejadas, e, como alguns dos próprios batuqueiros comentaram, aprender osmoticamente. Essas dinâmicas de aprendizagem musical se relacionam entre si e, muitas vezes, acontecem simultaneamente no decorrer das atividades do grupo.

\section{Escuta e tirar de ouvido}

Quando há a dificuldade em aprender algum elemento musical durante os ensaios ou oficinas, os integrantes recorrem às gravações de vídeo e áudio para 
escutar e tirar de ouvido. Ao comentar sobre seus processos de aprendizagem musical, Leojorge explicou: "Eu aprendi mesmo a tocar a coisa desse jeito, sentando, ouvindo o CD, sozinho em casa, sem ninguém. Aprendi a tocar o negócio como tava ali [no CD], foi o momento mais importante" (Leojorge, GF). Nesse caso, a escuta e o tirar de ouvido são considerados como um momento fundamental e complementar às práticas de aprendizagem musical.

A escuta e o tirar de ouvido, conforme descritos por Green (2002) constituem uma prática associada a um momento solitário, em casa, de acordo com os gostos e necessidades de cada um. Entretanto, nesta pesquisa podemos associá-la com uma prática que os participantes desenvolvem exercitando a escuta e a aperfeiçoam no convívio prolongado durante as próprias práticas musicais.

A escuta constante desenvolve a percepção musical dos participantes que, com o passar do tempo, tendem a apurar seus níveis de escuta e executar melhor seus instrumentos, distinguindo os demais e desenvolvendo suas capacidades técnicas. Portanto, essa dinâmica de escutar e de tirar de ouvido passa a ser uma influência não só nas práticas solitárias dos participantes como também nas atividades musicais do grupo, aprimorando os níveis de escuta durante os ensaios, oficinas e apresentações.

Foi possível constatar, no grupo focal e em relatos individuais, o quão significativa é essa prática para seus integrantes. Entre os músicos populares, escutar e tirar de ouvido músicas, arranjos ou trechos de música para aprender a executar ou aperfeiçoar suas habilidades musicais é um processo de aprendizagem musical significativo: envolve níveis de escuta e é associado a uma prática solitária (Green, 2002). A escuta musical é um processo de aprendizagem musical ao qual, consciente e inconscientemente, somos suscetíveis de influência no cotidiano. Intencionalmente ou não, estamos sujeitos a ouvir músicas das mais diferentes maneiras: caminhando na rua, dentro de um ônibus, no supermercado, com o vizinho ouvindo som alto, com um carro que passa, entre tantas outras.

Alguns participantes passaram a perceber, ouvir e identificar os instrumentos durante as práticas musicais, reconhecendo o aprimoramento dessa habilidade musical, e ainda resultando numa facilidade em tocar um instrumento. Green distingue três níveis de escuta: a intencional que visa a imitar, memorizar, 
escrever os acordes, cifras ou fazer algum tipo de anotação; a escuta atenta envolve o mesmo nível de atenção da intencional, mas sem nenhum objetivo específico de aprender a tocar, lembrar, comparar ou descrever algo depois; e a distraída, aquela sem nenhum objetivo nem atenção além de diversão e entretenimento, como uma música de fundo ou uma música que se ouve enquanto se executa outra atividade (Green, 2002, p. 24-25). Os níveis de escuta dos participantes são aprimorados à medida que praticam o maracatu regularmente. Assim, a escuta e o tirar de ouvido representam uma das cinco dinâmicas de aprendizagem musical caracterizadas neste contexto do grupo de maracatu Arrasta I/ha.

\section{Encontros casuais e organizados}

Os encontros casuais e organizados referem-se aos momentos em que os participantes do grupo interagem entre si. Essa dinâmica foi categorizada considerando os encontros casuais como um momento mais espontâneo dentro das práticas do grupo, e os encontros organizados como sendo as atividades musicais rotineiras: ensaios, oficinas e apresentações.

Os encontros casuais acontecem aleatoriamente nas atividades do Arrasta I/ha, de diversas formas e para diversos propósitos, conscientes ou inconscientes, intencionais ou não, e podem ser observados antes, durante e depois dessas atividades organizadas, por isso a opção de descrever tal dinâmica como "encontros casuais e organizados".

Os encontros casuais consistem em conversas paralelas entre duas ou mais pessoas, tanto para tirar dúvidas sobre como se toca um instrumento, um arranjo ou como se canta determinada toada. Às vezes, pode ser apenas um momento de descontração em que alguém escolhe um instrumento para improvisar, se divertir, cantar, dançar ou tocar livremente. Os encontros organizados são as próprias atividades organizadas, como: ensaios, oficinas e apresentações, e que acabam proporcionando esses encontros casuais. 
A presença de duas ou mais pessoas já resulta num encontro casual. Por um lado, o encontro não é casual, porquanto as pessoas têm um compromisso marcado, estão organizadas para que aconteça o encontro. Mas por outro, trata-se da dinâmica do grupo, em que cada um chega num momento diferente do horário combinado, proporcionando encontros e desencontros casuais entre os participantes.

Os encontros casuais não ocorrem somente antes, depois ou nas pausas das atividades; há também interações mais rápidas, como uma conversa paralela durante as atividades. Enquanto acontece um ensaio, oficina ou até mesmo uma apresentação, os participantes trocam olhares, gestos e, muitas vezes, palavras entre si para aprender ou relembrar algo sobre a toada que está sendo tocada. Perguntam ao membro mais próximo como é um determinado arranjo, célula rítmica ou trecho de letra enquanto já estão executando ou prestes a iniciar.

Essa vivência mostrou como são importantes esses encontros casuais, acontecendo das mais diversas formas e proporcionando momentos espontâneos de uma aprendizagem focada quase sempre numa dúvida pontual de alguma pessoa. Outro ponto interessante é que, nesses encontros casuais, nem sempre quem ensina é alguém mais experiente ou que tem a função de ensinar, mas alguém que já tem um conhecimento específico de algum conteúdo e que assim pode transmiti-lo para alguém que ainda não o tem. Esses encontros casuais e organizados proporcionam um ambiente de aprendizagem musical através das interações entre os participantes, pessoas interessadas em aprender que compartilham e trocam ideias e conhecimentos.

Durante esses encontros organizados, já programados pelo grupo, referidos aqui como "organizados", foi possível observar também os "encontros casuais", tais como descritos por Green (2002). Para a autora, entre os músicos populares da sua pesquisa, essas interações acontecem com mais frequência nos primeiros estágios de aprendizagem, quando formam as primeiras bandas e se encontram com outros amigos músicos.

No grupo Arrasta Ilha, os estágios de aprendizagem se misturam com a entrada de novos integrantes juntando-se aos mais antigos, culminando nesses 
encontros casuais e organizados como uma das dinâmicas de aprendizagem musical mais comuns entre os participantes nos ensaios, oficinas e apresentações.

\section{Observação e imitação}

Os processos de observação e imitação a que nos referimos aqui constituem dinâmicas de aprendizagem musical que podem ser tanto uma ação simultânea como uma ação consequente. Ou seja: a imitação às vezes é imediata ao ato de observação, e em outros momentos, primeiro alguém observa e depois imita determinada atividade. Essa dinâmica também está presente nos ensaios, oficinas e apresentações, sendo possível observá-la constantemente nessas práticas.

Durante as práticas musicais do grupo os batuqueiros acompanham por gestos e imitam os movimentos de quem está ensinando. O repertório do grupo vai sendo transmitido para os participantes durante os ensaios e oficinas, através de demonstrações individuais e coletivas, repetidamente. Como diz uma das integrantes do grupo: “meu método de aprendizagem é a prática” (Janaína, GF). Essa relação da observação seguida da imitação na aprendizagem musical é descrita por Prass (1998), quando investigou práticas de aprendizagem musical numa bateria de escola de samba de Porto Alegre:

[...] a imitação engloba uma escuta imitativa que acompanha a observação dos gestos de maneira simultânea, trabalhando interiormente com imagens aurais que são recursos que serão acionados sem a presença do imitado, à medida que o imitador construiu internamente essas referências (Prass, 1998, p. 158).

A maioria dos ensaios e oficinas do grupo inicia em formato de roda, em rotina que faz parte da rotina do grupo, para que todos possam se observar, facilitando essa prática da observação e imitação das execuções musicais. Quando estão em roda tocando e praticando, normalmente todos já estão tocando e, ao mesmo tempo, procurando imitar uns aos outros. Enquanto alguns já sabem, outros estão aperfeiçoando, e outros ainda estão inseguros em seus instrumentos. 
Essa prática coletiva, em roda, favorece essas autoanálises, uns influenciam os outros nos gestos, nos olhares, observando e imitando.

Os processos de observação e imitação acontecem entre todos os batuqueiros, não somente com quem está ensinando, pois muitas vezes o batuqueiro ao lado, ou próximo, já passa a ser uma referência para essa dinâmica, tantos nos acertos como nos erros de execução.

Uma coisa que eu acho massa disso é você ver e analisar como a outra pessoa toca porque você tá ali ajudando e você vai meio que aparando as suas arestas assim... Eu tava assistindo domingo passado agora um colega que tava aprendendo, e eu tava servindo como uma singela referência pra ele, e você vê a dificuldade do iniciante ali... Fazer aquele simples movimento parece tão difícil (André Brandão, GF).

Segundo Prass (1998, p. 156), tal dinâmica de observar e imitar costuma estar ligada à repetição como um recurso da aprendizagem musical. No Arrasta I/ha, ela se estabelece na rotina do grupo durante os encontros casuais e os organizados.

Os músicos observam e imitam uns aos outros, assim como os músicos mais experientes, conversam sobre música e formam bandas nos primeiros estágios de aprendizagem. Através dessa interação, os músicos copiam e trocam ideias, conhecimentos e técnicas, aprendem a tocar juntos, inclusive tocando covers, improvisando e compondo suas próprias músicas. Todas essas atividades de escuta e imitação influenciam tanto os indivíduos como os grupos nas suas práticas musicais (Green, 2002, p. 97). ${ }^{2}$

Essa dinâmica, tal como observada nesta pesquisa, se aproxima da escuta e imitação descrita por Green (2002), porque há uma escuta atenta com a intenção de imitar algum elemento musical durante as práticas do grupo. No grupo de maracatu Arrasta Ilha este tipo de escuta transcende a prática solitária e

\footnotetext{
${ }^{2}$ Do original: "Musicians watch and imitate each other as well as more experienced players, they talk about music and they form bands at very early stages. Through such interaction they copy and exchange ideas, knowledge and techniques, learn to play together, including making covers, improvisations and compositions of original music. All their listening and copying activities feed into both their individual and their group music-making" (Green, 2002, p. 97).
} 
não é exclusiva aos iniciantes, já que os níveis de escuta são recorrentemente apurados nessas aprendizagens entre pares, grupo e encontros.

\section{Onomatopeias solfejadas}

As "onomatopeias" estão associadas à formação de uma ou de mais palavras com base na reprodução aproximada dos sons (Houaiss; Villar, 2001, p. 2067). Essas onomatopeias consistem em sílabas que estão associadas às sonoridades dos instrumentos e costumam ser solfejadas, cantaroladas, das mais diversas formas, pois acabam por substituir frases explicativas de como se faz ou como se toca um ritmo ou um instrumento de percussão ou uma melodia. 0 "solfejo" está relacionado como "entoar um trecho musical [...] cantarolar sílabas" (Houaiss; Villar, 2001, p. 2601).

A opção por nomear essa dinâmica de aprendizagem musical como "onomatopeias solfejadas" está relacionada à observação sobre o aspecto do uso das onomatopeias de forma cantarolada, solfejada, respeitando a acentuação e figura rítmica dos instrumentos. Convém salientar que, no grupo Arrasta I/ha, não são usadas exclusivamente onomatopeias: às vezes, elas são substituídas por pequenas frases que soam semelhantemente aos sons e aos ritmos dos instrumentos. No entanto, optamos por nomear essa dinâmica de aprendizagem musical dessa forma - onomatopeias solfejadas - como uma categoria no contexto deste trabalho.

Geralmente para um instrumento grave como a alfaia, usam-se sílabas com sonoridade mais fechada como: “cãn, ticãn, ticãn, cãn”. Já o gonguê tem um som muito agudo, e uma de suas células rítmicas características é representada pela frase: "que é que tu tem, zé", mas é cantada com muitas contrações das palavras, ficando uma frase quase incompreensível. Como se vê na Figura 1, a seguir, optou-se por transcrever entre parênteses as palavras mais contraídas que não representam as notas da célula rítmica.

Oportuno enfatizar que cada batuqueiro desenvolve suas próprias formas de solfejar, possibilitando infinitas combinações de fonemas e acentos, mas com a 
mesma finalidade: reproduzir o som do instrumento. A seguir, algumas transcrições musicais de células rítmicas com as onomatopeias solfejadas mais comuns utilizadas pelos próprios batuqueiros do grupo Arrasta I/ha.

Figura 2: Onomatopeias solfejadas usadas pelo grupo

(Fonte: Marcelino, 2014, p. 138)

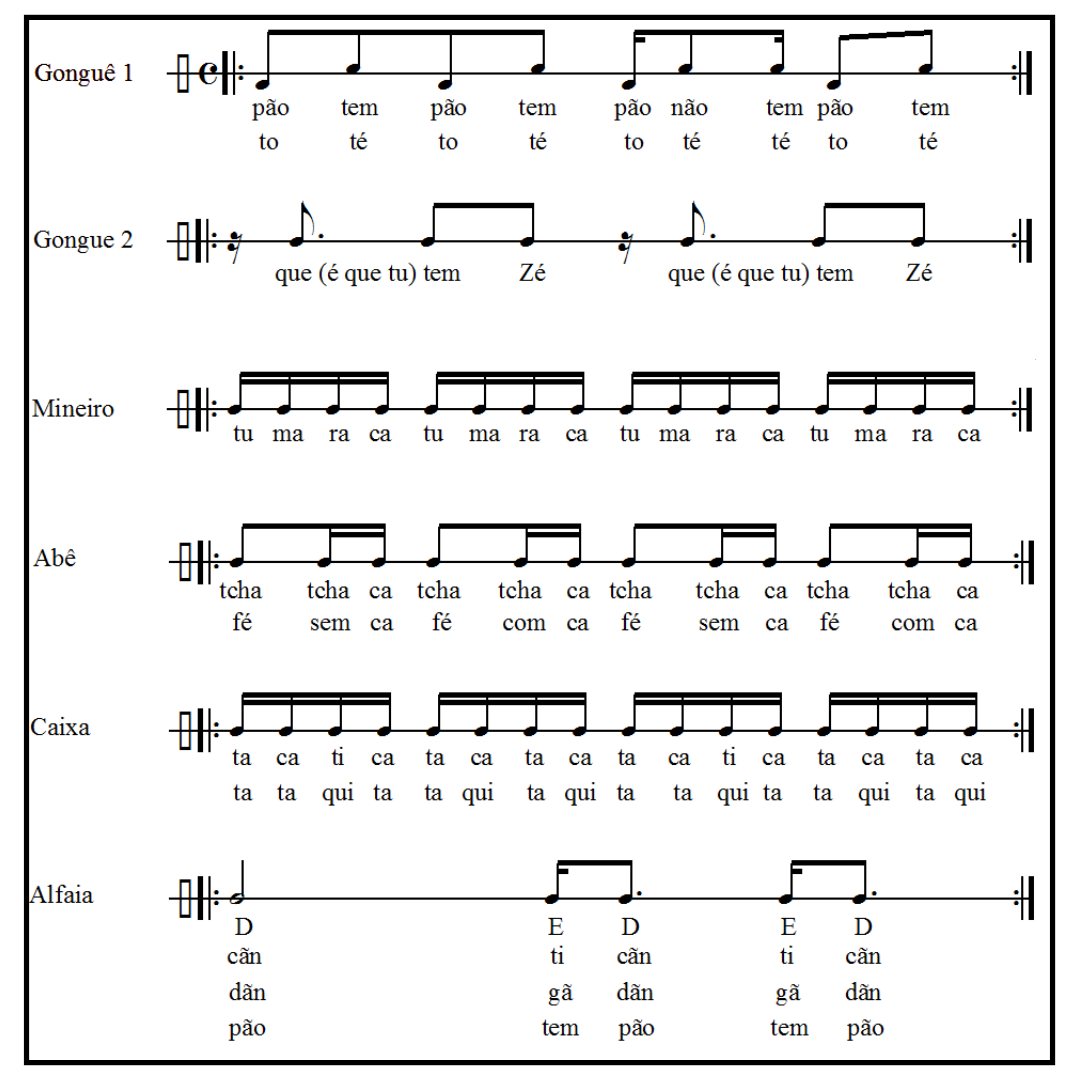

Conforme mostra a Figura 2, além do uso das onomatopeias solfejadas e de pequenas frases que representam a sonoridade de cada instrumento, há também o solfejo das letras “D” e "E”. Essas letras representam as mãos, direita e esquerda, as quais devem executar o ritmo. O solfejo das letras "D" e "E" é bastante usado para a aprendizagem das alfaias, pois no maracatu é o instrumento responsável pela maioria das variações rítmicas. É importante respeitar a 
manulação ${ }^{3}$ desse instrumento em especial, já que a movimentação, o timbre e a intensidade da mão direita são diferentes dos da mão esquerda.

As onomatopeias solfejadas são recursos observados frequentemente nas atividades musicais do grupo. Essa dinâmica está relacionada aos processos de observação e imitação descritos acima. Quando alguém demonstra algum ritmo para que outro observe e imite, acaba solfejando espontânea ou intencionalmente. Quando o grupo está tocando maracatu, o volume dos instrumentos costuma ser bastante alto, tornando muito difícil manter uma conversa entre duas ou mais pessoas. Assim, a expressividade, os gestos e também as onomatopeias solfejadas passam a ser uma alternativa no processo de ensino e aprendizagem nesse tipo de contexto com grupos de percussão. Tais processos são descritos também por Prass:

[...] o ensino e aprendizagem ocorrem praticamente sem a intervenção de palavras ou de frases sobre o que fazer e como. A transmissão ocorre basicamente através de sons realizados com os instrumentos ou com a voz, na forma de onomatopeias, ou ainda na expressividade do olhar e dos gestos corporais. Ensina-se e aprende-se música musicando (Prass, 1998, p. 149).

Freire (2005, p. 385) salienta que "associar sons a sílabas funciona como ferramenta no processo de transmissão oral da música, no ensino e como auxílio no processo de memorização de trechos musicais". Assim, destaca-se a relevância dessa prática de transmissão oral entre os participantes do grupo de maracatu Arrasta I/ha como uma das dinâmicas de aprendizagem musical identificadas.

\section{Aprender osmoticamente}

O termo "osmoticamente" está relacionado à palavra osmose, não em sentido literal, mas figurado. Segundo o dicionário, a palavra refere-se a um fenômeno biológico descrito como o "fluxo solvente de uma solução pouco concentrada, em direção a outra mais concentrada, que se dá através de uma

\footnotetext{
${ }^{3}$ Manulação é a maneira como as mãos executam um ritmo no instrumento.
} 
membrana semipermeável [...]" (Houaiss; Villar, 2001, p. 2087). Mas o termo empregado aqui, como uma das dinâmicas de aprendizagem musical, tem o sentido de uma absorção sutil ou gradual dos conhecimentos. ${ }^{4}$

Green (2002, p. 99-100) utiliza o termo "osmose" para descrever um processo natural de aquisição de habilidade e conhecimento musical dos músicos populares; todavia, nenhum músico de sua pesquisa utilizou tal termo, a autora estabeleceu essa relação como uma prática inconsciente dos músicos. Nesta pesquisa, alguns participantes do grupo Arrasta I/ha utilizaram o termo "osmoticamente" e "osmótico" nas entrevistas, quando procuravam descrever seus processos de aprendizagem. Sonia comenta:

A forma como a gente aprendeu no Arrasta a tocar maracatu é quase osmótico, assim... Você não sabe um trecho da letra, você aprende uma base, mas quando você está num transe, já está sabendo, você vai absorvendo aquilo (Sonia, GF).

A fala de Sonia revela como a aprendizagem é inconsciente até certo ponto, pois comenta sobre os processos de absorção de conhecimentos serem sutis e graduais.

Eu sinto assim, pra minha aprendizagem tem uma coisa de absorver. Tem esses momentos e tal de ouvir, de ouvir o Estrela [o CD do Estrela Brilhante], 'A não, olha ali aquela passagem, aquela convenção'. Um dia quando eu tava ali eu me toquei e falei: 'eu sei essa letra toda, eu sei esse passo', sabe assim?! Eu achei que um dia fosse difícil aprender tudo isso (Sonia, GF).

Ronan concorda com essa forma de aprendizagem musical descrita pelos participantes e acrescenta: "é osmótico, mas você querendo" (Ronan, GF). E Leojorge (GF) comenta que "em relação à didática do grupo, acaba sendo assim

${ }^{4}$ Como exemplo da frase "[...] ele nunca estuda, mas parece aprender por osmose", do original: "2. a subtle or gradual absorption or mingling: He never studies but seems to learn by osmosis". Disponível em http://dictionary.reference.com/browse/osmosis. Acesso em 21 nov. 2013. 
mesmo, a gente aprende osmoticamente". Sobre essa forma de aprendizagem, complementa citando diferentes dinâmicas, como na seguinte afirmação:

[...] de repente a gente tá tocando lá, começa a batucar, alguém grita a letra, e tu nem tá ouvindo a letra, tá tocando e você tá tentando ouvir, 'o que ele cantou mesmo?' Várias bocas mexendo. E de repente você puxa um amigo no cantinho e diz: 'me explica como é que é essa letra' (Leojorge, GF).

Nessa afirmação Leojorge se refere a situações comuns que acontecem no grupo, tais como: a necessidade de escutar a letra das toadas para imitar (escuta atenta), ou observar o movimento da boca de quem está cantando pra compreender qual é a toada que está sendo cantada (observação e imitação), ou ainda um encontro casual em que ele 'puxa um amigo no cantinho' para lhe ensinar a toada que está sendo cantada (encontros casuais).

Ao se engajarem nas práticas musicais do grupo, os participantes também passam por esse processo de enculturação. Aprender “osmoticamente," para esta pesquisa, é uma dinâmica de aprendizagem musical entendida como um processo natural de absorção de conhecimento através da imersão do indivíduo no contexto social.

Conforme mostra a Figura 3, a seguir, cada uma das dinâmicas de aprendizagem musical categorizadas nesta pesquisa se inter-relacionam entre as atividades musicais do grupo Arrasta Ilha de tal maneira que: ao solfejar algum elemento musical, ao observar ou escutar alguém tocar e procurar imitar, ao tirar de ouvido algum arranjo em casa, ou interagindo socialmente entre encontros casuais e organizados, o indivíduo passa a construir seu repertório musical, suas habilidades, técnicas e seus conhecimentos musicais, como um processo natural de aprendizagem musical. 
Figura 3: Dinâmicas de aprendizagem musical do grupo de maracatu Arrasta I/ha (Fonte: Marcelino, 2014, p. 144)

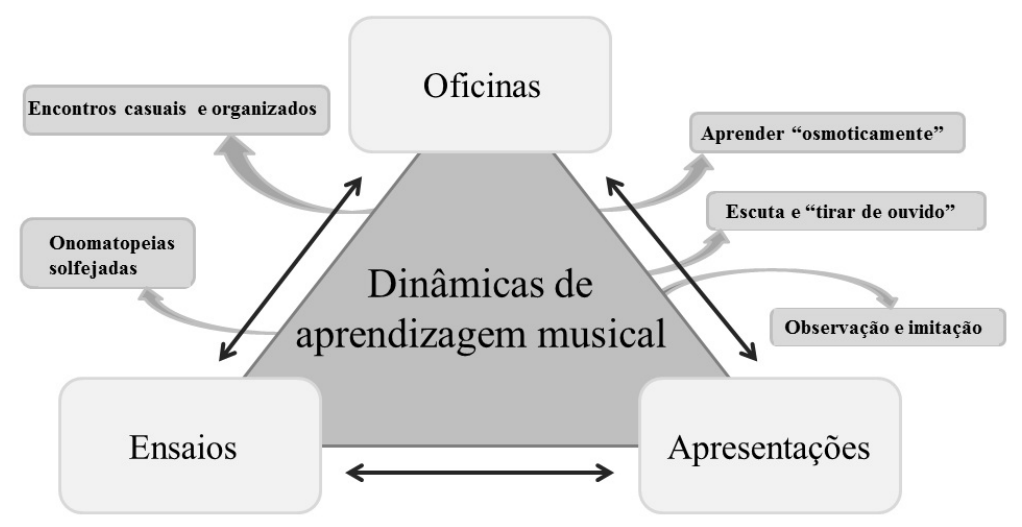

Essas dinâmicas de aprendizagem musical descritas são potencializadas dentro de um ambiente de aprendizagem que se configura como uma comunidade de prática, onde os participantes compartilham uma paixão em comum: o interesse pela prática musical do maracatu. Sem esse sentimento de comunidade essas dinâmicas não teriam a relevância e não transpareceriam nesta pesquisa.

Na busca do objetivo da pesquisa: investigar como se estabelecem as dinâmicas de aprendizagem musical entre os participantes do grupo de maracatu Arrasta I/ha, foi importante conviver por 8 meses através das observações participantes, o que permitiu categorizar essas dinâmicas e compreendê-las em suas especificidades e como se relacionam entre si.

A escuta e tirar de ouvido constituem uma dinâmica que transcende a prática solitária, já que os participantes aprimoram seus níveis de escuta à medida que praticam o maracatu. Os encontros casuais e organizados geram todas essas dinâmicas: os participantes interagem entre si, compartilham e trocam ideias entre pares e em grupos. Nessas atividades musicais os participantes executam com mais frequência o repertório do grupo, e o processo observação e imitação está associado às repetições das toadas e arranjos como uma das principais dinâmicas da aprendizagem musical. Ainda nesse processo de repetição e transmissão oral de conhecimento, as onomatopeias solfejadas se estabelecem como um recurso para 
compreender e memorizar as células rítmicas dos instrumentos de percussão. Esses espaços de aprendizagem promovidos pelo grupo - ensaios, oficinas e apresentações - sugerem o contato com essas dinâmicas de aprendizagem musical a partir da imersão dos participantes nessas práticas; aprendem osmoticamente como um processo gradual de absorção dos conhecimentos.

\section{Considerações finais}

Os participantes do Arrasta I/ha entram no grupo pelas mais diversas motivações e pretensões. No entanto, juntos compartilham uma paixão em comum e se interessam por tocar o maracatu, os ritmos e as toadas de diferentes nações de maracatu. Embora cada membro tenha suas preferências e objetivos, todos têm essa prática em comum: brincar o maracatu. Os integrantes se desentendem, discutem, se divertem; alguns se desligam do grupo, outros pedem pra entrar ou retornar, e tudo isso é discutido e negociado em reuniões, em conversas e na decisão de um consenso coletivo. Fatores que no início do convívio com o grupo pareciam caóticos, foram interpretados como questões comuns às comunidade de prática e as configuram, mobilizando interesses em participar do grupo.

Esses interesses e práticas interessam à educação musical, à medida que motivam e potencializam as aprendizagens musicais do grupo. Tal como reflete Green (2000), referindo-se às aprendizagens informais dos músicos populares, o conhecimento desses processos provoca o repensar da importância da enculturação no ensino e na aprendizagem de música, o potencial das relações de amizade em sala de aula, bem como atitudes e valores que permeiam nossas práticas musicais individuais e coletivas.

As atividades musicais do grupo - ensaios, oficinas e apresentações - se configuram como espaços de aprendizagem que movimentam as dinâmicas de aprendizagem musical no grupo. Essas dinâmicas estão inter-relacionadas, porquanto os encontros casuais e organizados são locais onde ocorre aprendizagem entre pares através de diferentes práticas categorizadas nesta 
pesquisa, como: observações e imitações, onomatopeias solfejadas, escuta e tirar de ouvido, além de, num processo natural consciente e inconsciente vão absorvendo osmoticamente habilidades e conhecimentos compartilhados.

No grupo de maracatu, observa-se que a articulação entre as dinâmicas de aprendizagem permitem que todos participem de forma significativa em diferentes níveis, impulsionando a apropriação, a mestria e o pertencimento. Segundo Sawyer (2008, p. 57), desta forma aprende-se mais do que os mecanismos da música, aprende-se também habilidades de interação, aprende-se a ouvir e responder de forma apropriada, aprende-se a colaborar e a comunicar-se em contextos sociais.

Ao categorizar as dinâmicas de aprendizagem musical desse grupo de maracatu, consideramos ter contribuído para ampliar as discussões acerca das características de processos de aprendizagem musical informal, no sentido de legitimar essas experiências em ambientes fora da escola. Como afirma Green (2002), é importante que essa abordagem seja considerada nos ambientes formais, e combinar essas duas - formal e informal - parece ser um caminho ainda a ser explorado nas práticas de educação musical em diferentes contextos.

\section{Referências}

ALVES-MAZZOTTI, Alda Judith; GEWANDSZNAJDER, Fernando. O método nas ciências naturais e sociais: pesquisa qualitativa e quantitativa. São Paulo: Pioneira Thomson Learning, 2001.

ANDRADE, Lucila Prestes de Souza Pires de. Aprendizagem musical no canto coral: interação entre jovens em uma comunidade de prática. Dissertação (Mestrado em Música - Área: Educação Musical) - Universidade do Estado de Santa Catarina. Programa de Pós-graduação em Música, Florianópolis, 2011.

ANGROSINO, Michael. Etnografia e observação participante. Porto Alegre: Artmed, 2009.

ARROYO, Margarete. Representações sociais sobre práticas de ensino e aprendizagem musical: um estudo etnográfico entre congadeiros, professores e estudantes de música. Tese (Doutorado). UFRGS, 1999.

Educação musical na contemporaneidade. Anais do II Seminário Nacional de Pesquisa em música da UFG. 2002a, p. 22 
. Mundos musicais locais e educação musical. Em Pauta, v. 13, n. 20, jun. 2002b, p. 95-122.

DEL BEN, Luciana. Múltiplos espaços, multidimensionalidade, conjunto de saberes: idéias para pensarmos a formação de professores de música. Revista da ABEM, Porto Alegre, v. 8, mar. 2003, p. 29-32.

FREIRE, Ricardo Dourado. Características e focos de aprendizagem de diversos sistemas de solfejo. ANNPOM - Décimo Quinto Congresso. 2005, p. 385-392.

GATTI, Bernardete Angelina. Grupo focal na pesquisa em Ciências Sociais e Humanas. Brasília: Liber Livro Editora, 2005.

GREEN, Lucy. How Popular Musicians Learn: a way ahead for Music Education. ASHGATE, 2002.

Poderão os professores aprender com os músicos populares? Revista Música, Psicologia e Educação, Porto n. 2, 2000, p. 65-80.

. Music, Informal Learning and the School: a new classroom pedagogy. ASHGATE, 2008.

GUERRA-PEIXE, César. Maracatus de Recife. São Paulo: Ricordi, 1956.

HOUAISS, Antônio; VILLAR, Mauro de Salles. Dicionário Houaiss da Língua Portuguesa. Rio de Janeiro: Objetiva, 2001.

MARCELINO, André Felipe. Grupo de maracatu Arrasta Ilha: dinâmicas de aprendizagem musical em uma comunidade de prática. Dissertação (Mestrado em Música - Educação Musical). Universidade do Estado de Santa Catarina. Programa de Pós-graduação em Música, Florianópolis, 2014. Disponível em:

$<$ http://www.tede.udesc.br/tde_arquivos/15/TDE-2014-06-03T181720Z-

1762/Publico/116065.pdf >. Acesso em 29 jul. 2014.

MÜLLER, Vânia Beatriz. "A música é, bem dizê, a vida da gente": um estudo com crianças e adolescentes em situação de rua na Escola Municipal Porto Alegre-EPA. Dissertação de Mestrado. Programa de Pós-Graduação em Música da UFRGS. Porto Alegre, 2000.

OLIVEIRA, Alda; HARDER, Rejane. Articulações pedagógicas em Música: reflexões sobre o ensino em contextos não-escolares e acadêmicos Clave, $\mathrm{n}^{\circ} 6$, nov. 2008, p. 70-83.

PRASS, Luciana. Saberes musicais em uma bateria de escola de samba: uma etnografia entre os "Bambas da Orgia". Dissertação (Mestrado). Programa de Pós-Graduação em Música da UFRGS, Porto Alegre, 1998.

RUSSELL, Joan. Perspectivas socioculturais na pesquisa em educação musical: experiência, interpretação e prática. In: Revista da Abem, n. 14, 2006, p. 7-16.

Sites of learning: communities of musical practice in the Fiji Islands. Focus Areas Report. Bergen: International Society for Music Education, 2002. 
SAWYER, R. Keith. Learning music from collaboration. International Journal of Educational Research, v. 47, 2008, p. 50-59.

STAKE, Robert E. Pesquisa qualitativa: estudando como as coisas funcionam. Tradução Karla Reis. Porto Alegre: Penso, 2011.

TORRES, Grace Filipak; ARAÚJO, Rosane Cardoso de. Comunidade de Prática Musical: Um estudo à luz da teoria de Etienne Wenger. In: R.cient./FAP, Curitiba, v. 4, n.1. jan./jun. 2009, p. 1-23.

WAZLAWICK, Patrícia; MAHEIRIE, Kátia. Sujeitos e músicas em movimentos criadores: compondo comunidades de prática musical. Revista da ABEM, Porto Alegre, v. 21, mar. 2009, p. 103-112.

WENGER, Etienne; LAVE, Jean. Situated learning: Legitimate peripheral participation. Cambridge University Press, 1991.

. Communities of Practice and Social Learning Systems. Organization, v. 7, 2000, p. 225-246.

Communities of Practice: Learning, Meaning and Identity. $18^{\text {th }}$ printing. Cambridge: Cambridge University Press, 2008.

Communities of Practice: a brief introduction. Disponível em: <http://wenger-trayner.com/Intro-to-CoPs/> (2006). Acesso em 03 jan. 2013.

WILLE, Regiana Blank. Educação musical formal, não formal ou informal: um estudo sobre processos de ensino e aprendizagem musical de adolescentes. Revista da ABEM, Porto Alegre, v. 13, set. 2005, p. 39-48. 